Procesos comunicacionales en la producción de hábitat: tres inflexiones para un abordaje decolonial

Fernando Vanoli, Virginia Martínez y Noelia Cejas

http://perio.unlp.edu.ar/ojs/index.php/question/article/view/4582

Cita sugerida: Vanoli, F., Martínez, V., y Cejas, N. (2018). Procesos comunicacionales en la producción de hábitat: tres

inflexiones para un abordaje decolonial. Question, 1(58), e042. doi:https://doi.org/10.24215/16696581e042

\title{
Procesos comunicacionales en la producción de hábitat: tres inflexiones para un abordaje decolonial
}

Communicational processes in the production of habitat: three inflections for a decolonial approach

Fernando Vanoli ferna.vanoli@gmail.com http://orcid.org/0000-0002-4599-725X Instituto de Investigación de Vivienda y Hábitat, Facultad de Arquitectura, Urbanismo y Diseño; Universidad Nacional de Córdoba/ Centro de Estudios Urbanos y Regionales; Consejo Nacional de Investigaciones Científicas y Técnicas. (Argentina)

Virginia Martínez mumymartinez@hotmail.com http://orcid.org/0000-0003-0978-6364

Centro de Investigaciones y Estudios sobre Cultura y Sociedad; Facultad de Ciencias Sociales; Universidad Nacional de Córdoba/ Consejo Nacional de Investigaciones Científicas y Técnicas (Argentina)

Noelia Cejas noelia_cejas@outlook.com http://orcid.org/0000-0001-9793-3031

Facultad de Ciencia de la Comunicación; Universidad Nacional de Córdoba/ Centro Experimental de Vivienda Económica; Consejo Nacional de Investigaciones Científicas y Técnicas/ Asociación de Vivienda Económica (Argentina) 


\section{Resumen}

Este ensayo reflexiona sobre procesos de producción de sentido que configuran las prácticas de construcción de conocimientos en un campo específico, como lo es el desarrollo de tecnologías para el hábitat. Desde una posición epistemológico-política que denuncia el proyecto civilizatorio de la modernidad y su modelo de producción de conocimiento, que antepone la palabra erudita a cualquier otro tipo de discursividad, trabajamos sobre tres niveles de abstracción-concreción que suponen claves de inflexión en el proyecto decolonial. Primero, la inflexión epistémica a partir de los aportes del proyecto decolonial, luego dos instancias de producción de sentido articuladas conceptualmente desde las ideas de silencio y expresividad corporal y, finalmente, nos interesa señalar técnicas de producción y expresión de conocimiento situado, como lo son el mapeo colectivo y la fotografía, poniendo el acento en las potencialidades de discursividades no logocéntricas. Las reflexiones expresadas en el texto provienen de la trayectoria de investigación del autor y las autoras en experiencias territoriales y situadas de construcción de tecnologías habitacionales, por lo que se articulan en el desarrollo algunas referencias empíricas con conceptualizaciones provenientes de los campos teóricos de los estudios sociales de la ciencia y la tecnología, el proyecto decolonial y la semiótica de la imagen.

Palabras clave: Proyecto decolonial; logocentrismo; cuerpo; fotografía; mapeo colectivo.

\section{Abstract}

This essay reflects on the production processes of meaning that shape knowledge construction practices in a specific field, such as the development of technologies for habitat. From an epistemological-political position that denounces the civilizatory project of modernity and its model of knowledge production, which puts the erudite word before any other type of discursivity, we work on three abstraction-concretion levels that imply keys of inflection in the decolonial project. First, the epistemic inflection from the contributions of the decolonial project, then two instances of production of meaning articulated conceptually from the ideas of silence and corporal expressivity, and finally, we are interested in accounting for production and expression techniques of situated knowledge, such as is the collective mapping and the photography, placing emphasis on the potentialities of non-logocentric discursivities. The reflections expressed in the text come from the research trajectory of the authors in territorial and situational experiences of construction of habitational technologies, for which in the development some empirical references are articulated with conceptualizations coming from the 
theoretical fields of the social studies of science and technology, the decolonial project and the semiotics of the image.

Keywords: Decolonial project; logocentrism; body; photography; collective mapping.

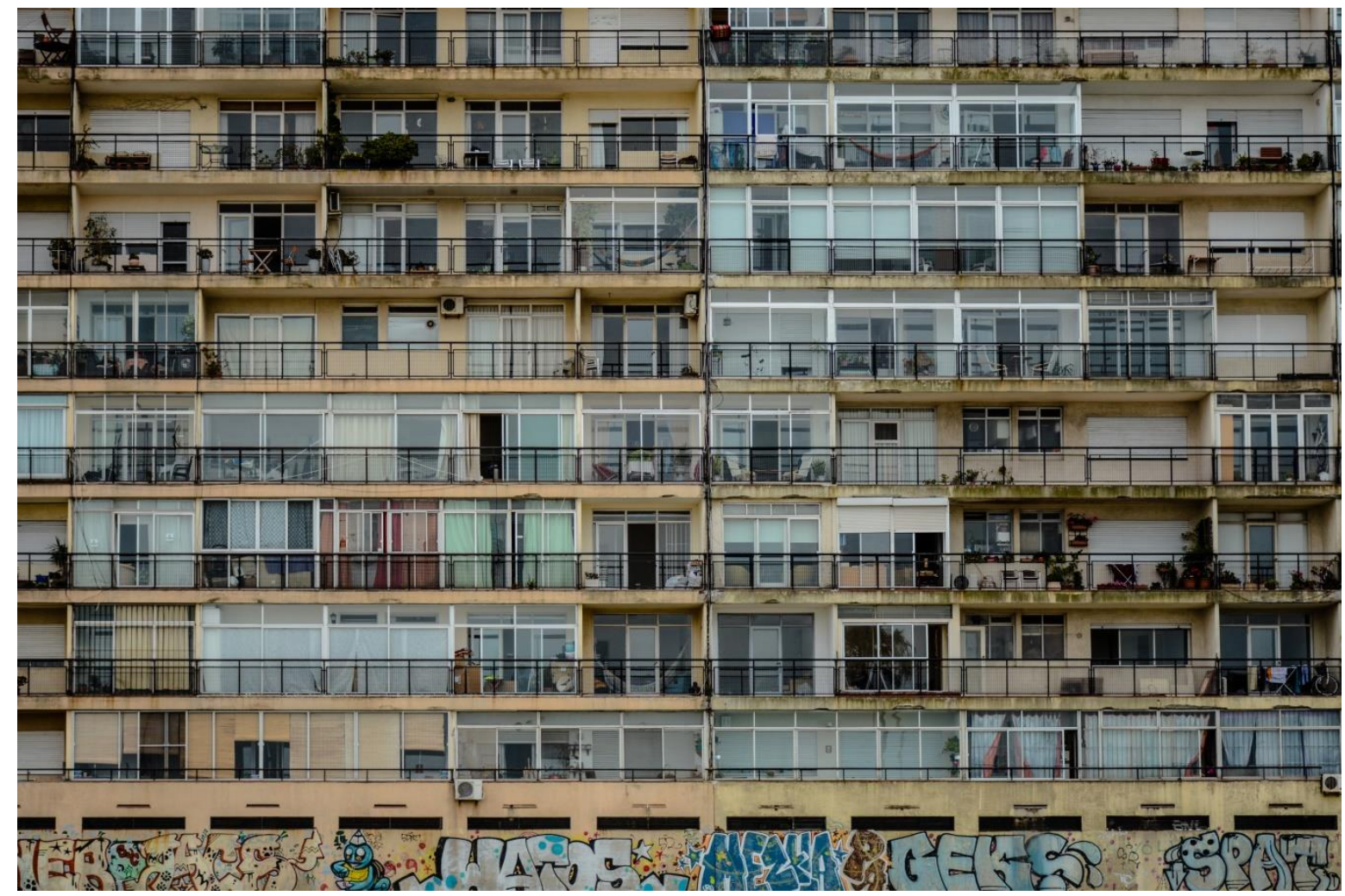

"Hábitat". Fotografía de Fernando Vanoli (2017). Rambla de Montevideo, Uruguay.

Aspiramos a generar una práctica basada en el silencio y no solo en la palabra. Aspiramos a sazonar la palabra con el silencio y con el ritmo de las cuerdas del telar o la guitarra. Generamos así un esbozo de normatividad tácita, en diálogo con y entre las creaciones de nuestras manos, de nuestros cuerpos. Así la ética se transforma en estética, en una plasmación de actos y pensamientos en objetos: libros, bolsas, tejidos, revistas, plantas, comidas... y fotografías

(Rivera Cusicanqui, 2015: 302-303) 
Este ensayo observa, de manera central, las prácticas comunicacionales, entendidas como procesos de producción de sentido, que configuran procesos de construcción de conocimientos en un campo específico, como lo es el desarrollo de tecnologías para el hábitat. Los alcances de este ensayo suponen el diálogo entre aportes provenientes de campos conceptuales (proyecto decolonial, estudios sociales de la ciencia y la tecnología, semiótica de la imagen) que abordan discusiones epistémicas y comunicacionales que enriquecen la reflexión y la práctica en procesos de producción de hábitat.

Las tecnologías son definidas aquí, desde la perspectiva de la tecnología social, como productos y procesos orientados a viabilizar procesos socio-productivos inclusivos (de allí la íntima relación con el campo de la economía social y su explícita denuncia y contraposición a las tecnologías capitalistas). Para ello, la tecnología social se funda en los principios de complementariedad de conocimientos (académicos, locales, populares, etcétera), adaptación a escalas pequeñas, autogestión y cooperación (Dagnino, 2014). Por su parte, tomamos una definición de hábitat que, sin equipararse con ellas, abreva de las tradiciones del campo de la producción social del hábitat y del hábitat popular. Desde una concepción amplia, la noción de hábitat refiere al ser y estar en la tierra. Esto va más allá de usar, ocupar, radicarse en o protegerse debajo de un artefacto tecnológico, puesto que el proceso dinámico de habitar resulta de la confluencia de planos diferentes, analíticamente distinguibles entre lo natural, social, económico, cultural, político, emocional, físico-espacial, tecnológico, entre otros. De manera que habitar está íntimamente ligado a la noción de construir, también desde su sentido amplio, paradigmático, reconociendo en cada uno de los y las agentes partícipes del proceso de habitar su capacidad intrínseca de producir significaciones en todos los órdenes señalados y otros que pudieran emerger en el proceso (Cejas, 2014).

La necesidad de repensar los procesos de producción de conocimiento en el campo del hábitat supone problematizar las prácticas con que usualmente se conciben las tecnologías habitacionales, más aun, las prácticas con que se construyen tanto el problema como las soluciones. Esas prácticas, entendidas como procesos comunicacionales, procuran complejizar la perspectiva heredada de transferencia de conocimiento tecnológico, entendiendo que la unilateralidad con que se definen las tecnologías destinadas a solucionar problemas habitacionales obtura los potenciales locales, componentes del acervo de conocimientos propio de los y las agentes que producirán o habitarán (si no ambas) el producto habitacional final. 
De manera específica, la perspectiva de los estudios sociales de la ciencia y la tecnología señala el fracaso relativo de experiencias transferencistas -especialmente aquellas que endilgan el "no funcionamiento" de artefactos "bien diseñados" a la incapacidad cultural de las poblaciones "adoptantes" (Thomas, 2011)- y nos provoca a pensar en modos de producción de conocimiento desde una matriz dialógica y territorialmente situada. Ese es el objetivo que perseguimos en este ensayo, en el cual intentaremos organizar algunos conceptos que emergen de experiencias de investigación (1) y el diálogo con perspectivas conceptuales contemporáneas.

Entendemos que la clave comunicacional es un punto de vista privilegiado a la hora de pensar los procesos participativos de producción de conocimiento, especialmente en tres niveles de abstracción-concreción que suponen claves de inflexión en el proyecto decolonial. En primer lugar, la inflexión epistémica que abordaremos desde los aportes del proyecto decolonial, procurando dar cuenta de la jerarquización gnoseológica propia de la modernidad/colonialidad. En segundo lugar, profundizamos en dos instancias de producción de sentido, invisibilizadas desde la matriz epistémica dominante, que articulamos conceptualmente desde la idea de silencio y la expresividad corporal. Finalmente, nos interesa dar cuenta de técnicas de producción y expresión de conocimiento situado, como lo son el mapeo colectivo y la fotografía, poniendo así el acento en las potencialidades de discursividades no logocéntricas.

\section{Inflexión epistémica}

El primer nivel de sentido que deseamos presentar remite al paradigma epistemológico o espacio de enunciación desde el cual asumimos nuestra práctica investigativa. Guba y Lincoln definen la noción de paradigma como un "sistema básico de creencias o visión de mundo que guía al investigador (sic), ya no sólo al elegir los métodos, sino en formas que son ontológica y epistemológicamente fundamentales" (2002: 113). En ese plano, comprendemos los procesos de producción de conocimiento, desde una lectura en clave decolonial (2). Como proyecto de pensamiento y acción, este invita a pensar los límites del paradigma de producción de conocimientos dominante (3). Castro-Gómez (2000) señala que las ciencias sociales han jugado -y juegan- un papel central en la consolidación del orden colonial, por lo que es necesario indagar en los mecanismos que operan en ese orden de producción de sentidos.

La situación de privilegio que se le otorga al campo científico remite a la estrecha relación con que se presenta el uso de la palabra, especialmente aquella estructurada desde la 
discursividad académica. El paradigma vigente de producción de conocimiento social sitúa a la palabra como el eje vertebrador de toda su producción, articulando allí las posibilidades de controlar el mundo de "lo real". Foucault, en Las palabras y las cosas (1968), define a la episteme como un horizonte de sentido temporal situado, un "a priori histórico", que ordena las condiciones de posibilidad para que unos discursos sean caracterizados como "conocimiento", mientras que otros no. Allí, el saber científico es una modalidad discursiva enmarcada en un horizonte epistémico -histórico y político- que opera como un dispositivo de control y jerarquización entre diferentes órdenes de sentido. Este dispositivo permite naturalizar el orden jerárquico que establece cuáles son los saberes autorizados para impulsar el devenir civilizatorio, distinguibles de otros saberes: incapacitados, no autorizados, o -en el mejor de los casos- pregoneros de modernidades incompletas, retrasadas y, por lo tanto, indeseables.

Desde este enfoque, nos interesa señalar los modos específicos con que la matriz colonial se expresa en nuestro campo de investigación, a fin de proponer algunas estrategias o perspectivas capaces de poner en situación de diálogo de saberes aquellos campos de experiencia históricamente invisibilizados o subalternizados. Para ello, proponemos explorar algunas formas de producción y expresión de conocimiento, significativos en nuestra experiencia de investigación, en tanto se nos revelaron como presentes, luego de larga invisibilidad. Entendemos, junto con Boaventura de Sousa Santos, que "no habrá justicia social global sin justicia cognitiva global" (2009: 12). Por ello, entendemos que los procesos de producción de conocimiento -orientado al desarrollo de tecnologías que pretende resolver problemas sociales, como es el del acceso al hábitat- serán transformadores en tanto subviertan las condiciones de tal producción; en otras palabras, el autor nos convoca a ampliar la mirada sobre el abordaje de la inclusión social incluyendo su nivel gnoseológico. Así, desde una perspectiva que va al encuentro de otras y otros agentes, otros campos de experiencia, otros saberes -emergentes de tales campos- se configura aquello que el autor denomina como un diálogo de saberes.

La dislocación de los órdenes gnoseológicos dominantes supone un reto político, epistémico, metodológico y conceptual, por lo que este diálogo de saberes debe ser comprendido como algo más que una técnica de investigación. Corridas/os de la definición etimológica de "diálogo" (eminentemente dual y logocéntrica), encontramos en esa perspectiva dialógica un posicionamiento orientado al encuentro con otras/os, donde el gesto de producción de conocimiento es compartido y el espacio de enunciación de cada agente se articula desde el principio de igualdad esencial (Vasilachis de Gialdino, 2007) (4). Esto lleva a la primera cuestión: ¿bajo qué condiciones es posible un diálogo de saberes? 
La posibilidad de desarrollar un proceso de construcción participativa de conocimiento enfrenta, casi en su primer movimiento, los límites de la deseable horizontalidad. Es que estos procesos no surgen desde un vacío, sino que se inscriben en el marco de experiencias que han torneado un tipo de relación social que, como se ha señalado, jerarquiza el saber académico por sobre otros campos de experiencia y saberes. Entendemos, desde esta perspectiva, que dicho tránsito -cuyo punto inicial es el de asumir el espacio político que inviste al rol de investigador o investigadora, inscripto en un devenir histórico que lo jerarquiza- requiere de un planteo metodológico que sea capaz de acompañar las profundas discusiones de orden epistémico y teórico que se vienen dando, críticas del orden instituido que privilegia unos campos de experiencia sobre otros.

Existen, en ese orden instituido que se espera transformar, "saberes no autorizados". Se trata de voces, saberes y experiencias que en el mejor de los casos son recuperados para ser traducidos, delimitados y retratados en la voz y el saber del campo de experiencia legítimo autorizado- para la producción de conocimiento: el saber científico. Este punto de subjetivación, que constituye esa relación de poder-saber, es el que requiere ser transformado. Entendemos que la transformación del actual modelo hegemónico de producción de conocimiento científico y tecnológico es una apuesta por la construcción de otro mundo, lo cual es ciertamente posible.

Entendemos que para ello es necesario hacer de los procesos de producción de conocimiento una práctica artesanal, capaz de alojar otras expresividades, producto de prácticas diversas. ¿Otras expresividades son capaces de subvertir el orden (epistémico) dominante? Pensamos que sí, o que al menos es posible indagar en otros modos de producción de sentido que desanden los modelos hegemónicos de producción y expresión de conocimiento. Nos lanzamos, así, a un universo de sentidos cuyo carácter común es la disolución de la primacía de la palabra, el vahído de sus privilegios y la oportunidad para darse al encuentro de otros mundos posibles, ya presentes, aún invisibilizados. La vastedad de la tarea exige la selección de algunos de estos campos posibles de sentido. Nos aproximaremos primero al silencio y a la expresividad de los cuerpos, para luego proponer recorridos tentativos y sensibles a partir de la indagación en el campo de la imagen, en lo que respecta a la producción de mapeos colectivos y la producción fotográfica. 
Inflexiones de producción sentido: el silencio y la expresividad de los cuerpos

El silencio

acecha mis palabras cuando quieren escapar de la atadura obligada, de la censura previa, de los testigos ocultos.

(Néstor Martínez)

Hay poemas dentro tuyo que el papel no puede tolerar. (Camila Urenda)

El pequeño fragmento de la poesía de Néstor Martínez hace resonar algunas cuestiones centrales relativas al poder de la palabra, entendidas en la clave que venimos señalando: hay una matriz de pensamiento, de producción y expresión de conocimiento, que remite a campos de experiencia y soportes discursivos privilegiados.

"Escapar de la palabra obligada", como quien escapa de un vórtice que acumula todo en un mismo flujo de sentidos, invita a reconocer que en ella -entendida como la palabra erudita, en un registro que es netamente académico- se resume la relación saber-poder en la que, además y especialmente, se inscribe la posibilidad de silenciar otras expresiones, otros campos de experiencia y producción de conocimientos. "Ataduras obligadas" en el campo académico, al menos por ahora, que son cuestionadas desde algunas líneas de pensamiento, como el decolonial.

En ese sentido, Rivera Cusicanqui (2015) invita a transitar la experiencia de reconocer y trabajar desde otras expresividades, como un ejercicio de subjetivación que subvierta ese orden, a través de una micropolítica de la investigación alternativa a la logocéntrica, entendiendo que si luego hay que volver a la palabra, el gesto de libertad ya está instalado. Transitar ese recorrido es una idea revolucionaria, que hace del silencio un universo vasto. Allí, 
la relación entre la palabra y el silencio es pensada como una solidaridad, ya no sólo como escucha o meditación previa sino como espacio creativo, habilitante de otros modos de vínculo, de otros lenguajes, otras sensibilidades y de otras temporalidades. En ese nivel entendemos que habita una micropolítica capaz de producir un devenir investigativo-político disruptivo del orden epistémico dominante.

Ese devenir integra dos movimientos sinérgicos. Por un lado, el de reconocer el silencio como efecto de silenciamiento y, por el otro, como la búsqueda de la comunicación, desanclada de la centralidad de la palabra, pero especialmente yendo al encuentro con aquello que habita en esos silencios, entendidos como espacios de sentido nutridos de experiencias y saberes diversos.

En el campo del hábitat, la producción de conocimiento situado del tipo que estamos señalando no se corresponde con la metodología de escritorio o tablero técnico exclusivo, sino que requiere del trabajo en territorio. En nuestras experiencias, y sin ánimo de entrar en detalles de cada caso, advertimos la diversidad de escenarios en los que este enfoque puede desplegarse. Esa diversidad se condice con la complejidad del campo del hábitat y nos convoca a encontrar espacios de diálogo, no solo sectoriales sino también trans-sectoriales. Es decir, no alcanza con la escala macropolítica estatal (del nivel que fuere) ni tampoco el exclusivo trabajo con las comunidades barriales. Es el interjuego interactoral el que permite ampliar la perspectiva con que se compone una lectura destinada a identificar tanto aspectos problemáticos como potencialidades locales que den lugar a la búsqueda de soluciones.

No obstante, ya sea que esta perspectiva de trabajo nos lleve al encuentro con funcionarios y funcionarias o técnicos y técnicas del Estado, o con trabajadores y trabajadoras de un taller, o con vecinos y vecinas de una comunidad, se repiten las marcas de la matriz relacional que venimos señalando. El diálogo de saberes, tomado en su definición más literal, produce una escena imposible de sostener; no importa que tan pretendidamente persuasiva pueda ser nuestra postura epistémica convocando a la producción participativa del conocimiento: en tanto reproduzcamos las prácticas consabidas no es posible transformar ese orden dominante. Walter Mignolo (2003) convoca a cambiar los términos de la conversación y no sólo los contenidos, es decir, plantea la importancia de pensar desde/con categorías de pensamientos, saberes y expresividades negadas o silenciadas por la retórica de la ciencia moderna/occidental/colonial. En la idea de términos de la conversación, entendemos además que subyace un cuestionamiento a las metodologías con que se instaura la relación en los territorios, aspecto ineludible e inescindible de este planteo teórico y epistémico. 
Esto supone desmantelar un dispositivo que se estableció desde la academia, que aun cuando busca atender problemáticas sentidas de injusticia social, no necesariamente logra detener la recurrente producción de subalternos y subalternas, a través de lógicas que no hacen más que reproducir la jerarquía con que se diferencian los campos de experiencia y saber: el extractivismo epistémico (Grosfoguel, 2015) que encierra la idea de informante, entrevistado o entrevistada, encuestado o encuestada, en fin, la innegable asimetría de ser "sujeto por conocer" (Vasilachis de Gialdino, 2007: 50) o la utilitaria relación de dominación en la que sólo se espera del otro u otra obediencia ante el saber "legítimo". Explotación y dominación, dos elementos permanentes en este fenómeno de poder (Quintero, 2014).

Estos roles pre-asignados con que se define a los y las agentes en diálogo, contiene una forma de silenciamiento potente. Instituye un modo de relación jerárquica, algo que Gayatri Spivak (2000) señala como la no-exterioridad entre el proyecto moderno colonizador y el (su) modelo de producción de conocimiento, incluyendo sus modalidades de representación. Esto implica que es necesario advertir que no se trata de recuperar voces, sino de trazar un modo de vinculación que permita un reconocimiento mutuo, de producir verdadera cercanía, entendida como una decisión política en la cual existe una toma de posición en la práctica efectiva de encuentro: asumir las diferencias, reconocer las trayectorias en la que se inscriben las relaciones que se pretenden alternativas y darse a la posibilidad de subjetivar en otros modos de encuentro.

Al reconocimiento de las formas en que se produce el silencio, como silenciamiento, le continúa la búsqueda de la comunicación, evitando la centralidad de la palabra en tanto ejercicio obligado para la expresión del saber y, por lo tanto, yendo al encuentro con aquello que habita en esos silencios. Entendemos que la búsqueda de ese encuentro, en tanto supone la transformación de la matriz relacional con la que se producen conocimientos (en la escala micropolítica), implica movimientos subjetivos que pueden experimentarse de manera problemática. Señalaremos al menos dos de ellos, la incomodidad y la sensación de dualidad (5).

Al silencio, no ya como efecto del silenciamiento sino como la búsqueda de la comunicación, le es inherente, en varias ocasiones, la incomodidad propia de aquello que descoloca, que transforma. El silencio, cuando es incómodo, no hace más que ponernos de frente a esa matriz relacional que obliga a unos/as y a otros/as a ocupar lugares pre-asignados. Por ejemplo, no es extraño ver repetida, en escenarios diversos, la sedimentada escisión entre el trabajo intelectual y el trabajo manual. La posibilidad de abrir el espacio de la producción del conocimiento implica un desplazamiento de los espacios pre-asignados y su consecuente 
incomodidad. Movernos de la oficina al taller o a la comunidad, transitar el silencio incómodo que se produce en el instante que alguien espera una instrucción, contener la tentación de llenar con palabras ese momento y descomprimir así el espacio para que lentamente vaya construyéndose la posibilidad del emerger de esos saberes empíricos no dejan de ser parte de esa incomodidad.

Entendemos que el diálogo de saberes requiere de la voluntad política de corrernos de los lugares de saber-poder, especialmente por parte de quienes los investimos. El carácter transicional con que entendemos ese diálogo requiere de un gesto político y volitivo, que en parte es reproductor de la asimetría consabida, de ahí la sensación de dualidad que señalamos. En algún punto depende de la voluntad de quien ejerce el poder de abandonar los dispositivos convencionales. Pero justamente por ser un gesto político decolonial, entendemos que se trata de una asimetría posibilitante, en tanto no depende de una voluntad que solapadamente reproduce relaciones verticalistas, sino que es un gesto que instituye otros modos de comunicación, como proceso de producción de conocimientos, asentado en la premisa de incompletitud de todo saber.

En ese punto emerge del propio territorio y de sus agentes la expresividad que puede resultar más fructífera. En una de nuestras experiencias de trabajo en taller, con constructores y constructoras, carpinteros y carpinteras, se nos hizo evidente que la expresividad de los cuerpos era el soporte discursivo ineludible en ese diálogo. Si en algún sentido nos preguntamos por los límites y las posibilidades de performatividad de la palabra, la expresividad de los cuerpos, compartiendo en un espacio común -como lo es el taller-, sitúa el diálogo de saberes a través de la contundencia de otros soportes discursivos, capaces de dar cuenta de saberes y campos de experiencia que escapan al registro logocéntrico académico.

Nos interesa entonces abordar esa discursividad específica, la de los cuerpos, como soporte de saberes que se revelan más allá de la palabra, o aun con ella.

Santiago Castro-Gómez y Ramón Grosfoguel (2007), señalan que todo conocimiento posible se encuentra in-corporado, encarnado en agentes atravesados y atravesadas por contradicciones sociales, vinculados y vinculadass a luchas concretas, enraizados y enraizadas en puntos específicos de observación, mientras que la idea eurocentrada del "punto cero" (6) obedece a una estrategia de dominio económico, político y cognitivo sobre el mundo, del cual las ciencias sociales han formado parte. En esta dirección, abordamos la frecuente y ya señalada escisión cuerpo-mente, piedra basal del dominio de la razón (moderna/colonial/eurocentrada) sobre otras formas del ser y del saber. 
La línea divisoria entre el campo epistemológico y otras gnoseologías parece estar dada por el rigor que otorga el método científico a la construcción de ese tipo de conocimiento, construido por un sujeto pretendidamente universal, a-histórico y etéreo. De alguna manera, la sistematicidad (7) que propone el uso del método científico en la construcción del saber académico aporta a delinear la idea de transparencia y objetividad, que se apoya en la posibilidad de verificar la rigurosidad con que fueron construidos los resultados.

Del otro lado de la línea que divide -y jerarquiza- al saber académico, se encuentran aquellos saberes que son producidos desde otros campos de experiencia, como puede ser el saber netamente empírico. A diferencia de la sistematicidad explícita con que se organiza el discurso sobre los saberes académicos, este campo de experiencia no contiene una estructura exhaustiva bajo la cual categorizar los saberes que a través de él se construyen. En experiencias de investigación con constructores y constructoras, carpinteros y carpinteras y/o o habitantes fuimos reconociendo con ellos y ellas que existen saberes que pueden ser definidos como un cúmulo de rutinas, destrezas, costumbres, modos de hacer, modos de organizarse en la tarea, usos de materiales y herramientas, movimientos corporales que han sido aprendidos 0 se han desarrollado en la propia experiencia (exclusivamente laboral o, en su perspectiva compleja y situada del habitar) y que puede ser evocado cada vez que es necesario. En el caso de constructores y constructoras y carpinteros y carpinteras, se trata de un proceso en el cual logran mejorar, ajustar o descartar algunos de esos saberes aprendidos y, especialmente, saberes que se expresan a través de sus cuerpos.

Si en el campo de experiencia académico existe algún tipo de univocidad respecto a los y las referentes del discurso dados por el estado del arte de cada disciplina, el campo de la experiencia empírica presenta pluralidad de referentes dados por las múltiples fuentes y posibilidades de producción de conocimiento. Ese proceso, con que se actualizan los conocimientos producidos en otras experiencias, en la práctica tiene un carácter, primordialmente, no verbal. Son conocimientos operados con el cuerpo, antes que con la palabra, y constituyen un campo de difícil paso al discurso lingüístico. Cuando eventualmente se produce ese pasaje, de la expresión corporal a la lingüística, es recurrente que emerja en textos narrativos y descriptivos.

Señalamos esto a fin de marcar otra diferencia respecto de los textos académicos (cuya producción se estructura en textos argumentativos, principalmente) pero además porque esta diferencia refleja un aspecto más interesante: esa expresividad da cuenta del propio ejercicio de producción de conocimiento, que muchas veces implica un relato que explicita el contexto espacio temporal en que determinado saber se fundó. Esta es una característica central, donde 
la remembranza de las prácticas a través de las que se construye un saber específico es, al mismo tiempo, la apertura de una caja negra que no siempre puede abrir el saber que emerge del campo académico dominante (8).

Así, un modo de producir conocimiento situado puede ser pensado desde la instancia de recuperación del espacio de enunciación, como un espacio de construcción y reivindicación de la identidad, en la dislocación de los órdenes jerárquicos que organizan la relación entre unos saberes y otros.

$\mathrm{Si}$, como viene siendo planteado, la dislocación de las jerarquías gnoseológicas requiere de espacios de producción de sentido capaces de subvertir el orden instituido, la capacidad de imaginar otros modos de establecer una comunicación deviene una condición necesaria. La propia idea de imaginación nos invita, a partir de las resonancias más evidentes de esa palabra, a indagar en la imagen como expresividad específica y en los modos de su participación en los procesos de producción de conocimientos.

\section{Inflexiones de producción y expresión de conocimiento situado no logocéntrico: el mapeo colectivo y la fotografía}

No creo que las palabras sean suficientes. El mundo está lleno de cosas que son muy difíciles de poner en palabras y que sólo una imagen puede describirlas en su profundidad

(Laurie Anderson)

En este nivel, entonces, nos interesa señalar dos espacios de producción de sentido cuya perspectiva de proceso comunicacional procura dislocar las jerarquías gnoseológicas instituidas. Estos son el mapeo y la producción fotográfica, ambas abordadas desde lógicas de producción alternativas a la lógica moderno/colonial.

La cartografía crítica o los mapeos colectivos suponen una herramienta de mucho valor para este tipo de propuestas. Incluso, si tomamos a los mapas como representación tradicional de la dominación -entendiendo que son parte de una construcción ideológica que históricamente se utilizó para apropiar, dominar y disciplinar a quienes habitan los territorios-, al pensarlos en clave participativa, por medio de procesos que recuperan saberes anclados en un territorio, se abre paso a un instrumento de creación o expresión de nuevos relatos, a partir de la experiencia y los saberes de quienes lo construyen. 
Deleuze y Guattari indican que "el mapa no reproduce un inconsciente cerrado sobre sí mismo, [sino que] lo construye" (1997:18); es decir, la construcción de mapas implica un momento de agenciamiento. En ese sentido, en su trabajo como parte del colectivo iconoclasistas, Risler y Ares plantean el proceso del mapeo como una instancia de creación que "subvierte el lugar de enunciación para desafiar los relatos dominantes sobre los territorios, a partir de los saberes y experiencias cotidianas de los participantes" (2013: 14). Así, entendemos que el uso de este tipo de herramientas gráficas forma parte de una propuesta metodológica que pondera la participación en la investigación, incorporando recursos visuales que amplían las formas de comprender y reflexionar la realidad cotidiana e histórica, impulsando la creación colectiva.

En ese mismo sentido, la producción gráfica que habitualmente realizan carpinteros, carpinteras, constructores y constructoras es otra forma de expresión de conocimiento subalterizada o invisibilizada: el croquis de componentes, el surco en la tierra por donde se excavarán fundaciones, las marcas con alambres por donde pasarán instalaciones, etcétera. Nada de eso parece tener la relevancia de la expresión gráfica autorizada, es decir la que producen los o las agentes con saber técnico-académico: la planta arquitectónica, el plano de estructuras, la simulación de comportamiento térmico, el detalle de uniones o vínculos, etcétera.

Como plantea Rivera Cusicanqui (2015) es interesante pensar en la imagen como práctica de comunicación horizontal. Con ese enfoque, la práctica de producción fotográfica puede ser aliada de la investigación en el trabajo de campo y en la producción de conocimiento con nuestros interlocutores e interlocutoras. De manera subyacente, entendemos que la fotografía es una técnica de producción de sentido que puede vehiculizar un proceso comunicacional decolonial.

De esta manera, reivindicamos la imagen en su discursividad específica, en contraposición a la tradicional utilización como referencia del texto que convalida la lógica de la escritura alfabética. Roland Barthes (1968) ya decía que, a pesar de la abundancia de imágenes que nos rodean en la actualidad, difícilmente podríamos definirnos como una civilización de la imagen, ya que en la mayoría de esas imágenes el texto está presente, ya sea en forma de título, de referencia, en globo de diálogos, mensajes publicitarios, en la prensa, etcétera. En ese sentido el autor invita a revisar la potencial autonomía propia del lenguaje visual, que puede estar relacionado al texto pero no necesariamente supeditado al mismo.

Partiendo de esa idea de potencialidad, planteamos a la imagen como portadora de una entidad y narrativa propia, lo que implica "liberar lo visual de las ataduras del lenguaje" (Rivera Cusicanqui, 2015: 23). Reconocer a la imagen como una expresión distinta a la del lenguaje 
escrito, y también como portadora de un relato que condensa otros sentidos, nos convoca a explorar nuestras subjetividades, a movilizar la percepción y las emociones que han sido oprimidas por nuestro aprendizaje racional. Es ahí donde la escritura no es castigada en sí misma, sino en su construcción racional, de una modernidad alienada, donde la mirada crítica a partir de la imagen es una posible resistencia.

Rivera Cusicanqui abre, a propósito de la producción fotográfica, un espacio de reflexión potente al momento de configurar la apuesta política con la que llegamos al encuentro con otros/as en el proceso de producción de conocimiento. De un modo más específico, la propuesta de trabajar con la cámara o con las imágenes, es un intento metodológico de incorporar estos planos sensibles en la construcción de conocimiento. La cámara pone conciencia en la mirada de quien enfoca y quien es observado u observada por el lente. La incomodidad producida por esa situación y ese molesto aparato, pone en evidencia la necesidad de construir una confianza capaz de dejar fluir un diálogo en esa circunstancia. Nos atraviesa, comenzamos a mirarnos en el acto de mirar a otras personas, nos interpela en nuestro rol, e ilumina lo no dicho del orden relacional. Rivera Cusicanqui dice:

\footnotetext{
Volverse un intruso consciente de una intrusión (con la cámara) le permite desplegar acercamientos horizontales y aceptar que al observar, se es también observado, evaluado en el gesto, en la apariencia y en los modales, de modo que puede corregir sus gestos y lograr un acercamiento humanamente significativo y no sólo metodológicamente correcto (2015: 311).
}

Este tipo de metodología en la investigación, reconfigura el rol de quien investiga, participante de una situación en la que se acerca a observar con la cámara en mano para registrar. Hacer consciente esa presencia y el modo en el cual se la configura en el encuentro con otros y otras se entrelaza con la capacidad de generar la confianza y de repensar qué vínculos estamos produciendo en nuestras prácticas investigativas.

De este modo, apostamos por una perspectiva dialógica que posibilite incorporar la imagen en tanto promueve otros devenires subjetivos en la producción de conocimiento colectivo. Carli plantea que el uso de la imagen "parece traer nuevamente la inquietud por la relación entre poesía y filosofía" (2014: 85), aludiendo a la posibilidad de superar fronteras entre arte y conocimiento académico. Allí, la idea de lo visual, aporta a construir lo sensible del "arte", en términos de nuestros procesos de investigación. Así, incorporar la noción de visualización 
implica retomar una forma de memoria que condensa otros sentidos de los/as sujetos/as con quienes trabajamos, una memoria estrechamente ligada a la experiencia vital.

Sin embargo, consideramos que la mediación del lenguaje que heredamos de la tradición colonial/moderna disminuye la capacidad de expresarlo. La descolonización de la mirada implicaría recuperar el sentido de la experiencia, tanto corporal como mental. "Sería entonces una suerte de memoria del hacer, que como diría Heidegger, es ante todo un habitar. La integralidad de la experiencia del habitar sería una de las (ambiciosas) metas de la visualización" (Rivera Cusicanqui, 2015: 22-23).

Los mapeos colectivos, la fotografía, la imagen como síntesis expresiva que condensa múltiples sentidos y que no pretende divorciarse de la palabra, sino, potenciarla e incluso transformarla, retoman el gesto de libertad que mencionamos anteriormente, gesto que tiene la posibilidad de instalarse en la escritura superando, en gran medida, los límites que señalamos al empezar este texto.

\section{Palabras finales}

Las prácticas de producción de conocimiento operan desde una cuestionable matriz epistemológica que invisibiliza o subalterniza los campos de experiencia de agentes igualmente invisibilizados e invisibilizadas o subalternizados y subalternizadas. Proponer el ejercicio de prácticas situadas de producción de conocimiento no deviene simplemente de una provocación de orden moral, no se trata de un ejercicio solapado de reproducción de la matriz vincular asimétrica, que se acerca a otros y otras agentes para "darles voz". Por el contrario, salirse de ese modo relacional, aun con los vestigios que conservemos en este proceso de transición y de transformación hacia otros modos posibles, consiste en reconocer la autonomía con que cada agente despliega sus campos de sentido y advertir que el diálogo, abierto a nuevos criterios de jerarquización entre conocimientos, es un aspecto que complejiza y abre nuevas posibilidades para la resolución de problemáticas sociales.

En ese sentido, conjurar las prácticas coloniales de producción de sentido -logocéntricas- y sus modelos comunicacionales -oscilante entre modelos transferencistas y extractivistassupone la búsqueda de prácticas alternativas. Entendemos que esto supone un devenir, que como toda transición recreará y creará elementos tanto del orden dominante como alternativo. Los potenciales de transformación radican en la apuesta política que hemos mencionado anteriormente, aun con sus incomodidades y dualidades. En ese sentido señalamos el carácter 
transicional con que se entiende el diálogo de saberes, que en parte requiere de la reproducción de la asimetría, posibilitante del encuentro. Entendemos que se trata de una definición no sólo epistémica, sino metodológica y transversalmente política. Esa posición política de la propuesta nos recuerda al Calibán, un personaje de William Shakespeare, en la obra teatral "La Tempestad". Este personaje, muchas veces recuperado en la filosofía latinoamericana, encarna buena parte de este gesto transicional: éste, siendo el personaje dominado al que se le impone el uso de una lengua, es también quien la aprende para usarla como un arma, para maldecir al dominador/a con ella. Dice Liendo (2015: s/p sobre esto: "En un gesto poscolonial, el subalterno emerge de su condición y cambia de signo axiológico una estructura de dominación, en este caso, la lengua para usarla como una potente reafirmación de sí". Desde ese gesto planteamos un necesario escenario de disputa, pero advirtiendo que no es ese el horizonte. Es decir, retomando la contundente frase de una feminista negra, Audre Lorde, quien en una conferencia en Estados Unidos en 1979 señalaba: "Las herramientas del amo, nunca desarmarán la casa del amo".

Entendemos que es importante esta instancia de transición, que permita poner en la superficie de lo audible, lo visible, lo inteligible y lo ponderable de otras formas de producción y expresión de conocimientos. Por esto, nos interesa el presente, ese es el escenario de resistencia y transformación: nos afirmamos en un presente donde el potencial de la acción y el pensamiento se encuentra imbricado a este espacio de lo múltiple y lo contradictorio. Ahí es donde intentamos una forma de elaborar la cercanía, el interconocimiento a través de marcos epistemológicos sensibles y perspectivas metodológicas capaces de producir una cercanía no instrumental.

No obstante, conscientes también de esa transición, en nuestras experiencias advertimos que el exceso de palabras dichas (tan afín a nuestro habitus académico) plantea una asimetría muchas veces insalvable, en el encuentro con compañeras y compañeros que entretejen sus relaciones por medio de, digamos, otros soportes discursivos. $Y$ con esto comprendemos que mora en la palabra cierta utopía comunicacional. En ese sentido, creemos que una metodología que abogue por la cercanía es aquella que permita el encuentro y, antes que las palabras, que estimule la presencia activa de otras subjetividades.

Acentuamos en este punto la dimensión corporal de esas subjetividades que aloja y expresa la afectividad y las emociones. La idea de "cercanía" que invocamos a lo largo del texto involucra así la co-presencia de corporalidades en los procesos de producción de conocimientos. Allí, el taller $\mathrm{o}$ el encuentro con familias -con su temporalidad dilata y su espacialidad amplia- 
instituyen un tiempo/espacio diferente y necesario para la construcción de confianzas, cariño, respeto, conocimiento recíproco, imprescindibles para la producción efectiva de esa cercanía. Sostenemos, entonces, que sólo un proceso de producción de conocimientos (orientado al desarrollo de tecnologías para el hábitat en nuestro caso) que abra paso a esas subjetividades corporalizadas -y con ello a diversos saberes y modos de expresión- será capaz de desplegar una micropolítica que produzca un devenir investigativo-político disruptivo del orden dominante. Y por orden dominante ya no nos referimos exclusivamente al orden epistémico, sino también a todos aquellos órdenes instituidos que condicionan las posibilidades de engendrar otro mundo, ciertamente deseable, y posible.

\section{Notas}

(1) Quienes escribimos el artículo compartimos experiencias de investigación, a la vez que desarrollamos trabajos en otros equipos. El factor común remite al campo del hábitat, subrayando el enfoque territorial, situado, de producción de conocimiento. En general estas experiencias suponen la articulación con trabajadores y/o habitantes de las comunidades con quienes abordamos la problemática habitacional/laboral/tecnológica/cultural, articulando con el trabajo de otras instituciones que participan en el territorio: desde entidades gubernamentales del estado, $u$ otras entidades de Ciencia y Tecnología como universidad, Instituto Nacional de Tecnología Agropecuario (INTA) o Instituto Nacional de Tecnología Industrial (INTI) u otras organizaciones sociales.

(2) Dicho brevemente, los fundamentos de esta perspectiva señalan que la modernidad, entendida como modelo civilizatorio global, se encuentra estrechamente ligada a la historia del colonialismo y de la colonialidad (Lander, 2000). El fin del colonialismo, entendido como el estadio histórico en el cual se disuelve el vínculo legal entre metrópoli y colonia, no dio paso a la disolución de la matriz vincular de dominación. Si en el período de la colonia el ejercicio legítimo del poder se fundaba en la legalidad del lazo político, el colonialismo prevalece a través de la actualización de la matriz de producción de sentido eurocentrado, que configura un modo de organización geopolítica orientada a sostener la superioridad de los denominados "países desarrollados". La modernidad, así, puede ser comprendida como un modelo civilizatorio en el que se configura un nosotros (moderno y masculino) con facultad de intervenir en territorios, grupos, conocimientos, prácticas, subjetividades; y que en la diferencia constituye un otro no-moderno. El reparo en esa exterioridad, denominada "diferencia colonial", permite reconocer las naturalizaciones presentes en el discurso de la modernidad/colonialidad.

(3) Esta idea remite al concepto de "colonialidad del saber"; la misma refiere a nociones desarrolladas especialmente por Lander (2000) y Mignolo (2007), quienes pretenden dar cuenta de una geopolítica del conocimiento, cuya hegemonía epistémica surge del singular poder de nombrar por primera vez, de crear fronteras, decidir cuáles conocimientos y comportamientos son legítimos o no y establecer la propia mirada sobre el mundo como la mirada dominante.

(4) Vasilachis señala el principio de igualdad esencial como piedra basal de su reflexión meta epistemológica, en la que plantea el diálogo de saberes entre sujeto conocido y sujeto cognoscente. Para mayor profundización en el planteo, se sugiere consultar la bibliografía señalada de la autora.

Question, Vol. 1, N. ${ }^{0}$ 58, abril-junio 2018. ISSN 1669-6581

Instituto de Investigaciones en Comunicación | Facultad de Periodismo y Comunicación Social | Universidad Nacional de 
(5) Se completará el sentido de esta categoría a continuación, no obstante nos interesa señalar su origen. Optamos por esta noción basándonos en aportes de Paulo Freire, quien señala en Pedagogía del oprimido (Freire, 1970: 4): "El gran problema radica en cómo podrán los oprimidos, como seres duales, inauténticos, que 'alojan' al opresor en sí, participar de la elaboración de la pedagogía para su liberación. Sólo en la medida en que se descubran 'alojando' al opresor podrán contribuir a la construcción de su pedagogía liberadora".

(6) "Hybris del punto cero" es una noción que Santiago Castro-Gómez (2005) plantea para describir la mirada epistémica/colonial sobre el mundo. Como matriz de producción de conocimiento, erige a un observador privilegiado, pretendidamente posicionado por fuera del mundo (punto cero) a fin de aplicar su mirada analítica, pretendidamente orgánica (de ahí hybris, el pecado de la desmesura en la tradición griega).

(7) Entre los mecanismos de validación y verificación de saberes académicos se emplean tanto articulaciones lógicas como por contrastación empírica. Sin embargo, a diferencia de aquello que aquí llamamos saber empírico, en el campo académico todo mecanismo de validación se articula en un modelo sistemático de orden nomotético, que constituye un instrumento central para la producción/reproducir del conocimiento (Cejas, 2014).

(8) Rivera Cusicanqui, a lo largo de La epistemología y sus formas cambiantes (2003), analiza las implicancias del proceso con que se construye el campo epistemológico como forma gnoseológica superior, analizando críticamente al desarrollo del método científico y su profunda atención al contexto de justificación, en detrimento del contexto de descubrimiento, en su carácter contingente.

\section{Bibliografía}

Barthes, R. (1986). Lo obvio y lo obtuso: Imágenes, gestos, voces. España: Editorial Paidós.

Castro-Gómez, S. (2000). Ciencias sociales, violencia epistémica y el problema de la "invención del otro". En Lander, E. (Ed.). La colonialidad del saber: eurocentrismo y ciencias sociales. Perspectivas Latinoamericanas. Buenos Aires: CLACSO.

Castro-Gómez, S. (2005). La hybris del punto cero. Ciencia, raza e Ilustración en la Nueva Granada (1750-1816). Bogotá: Centro Editorial Javeriano, Instituto Pensar.

Castro Gomez, S. y Grosfoguel, R. (2007). Prólogo. Giro decolonial, teoría crítica y pensamiento heterárquico. En Castro-Gómez, S. y Grosfoguel, R. (Eds.). El giro decolonial: reflexiones para una diversidad epistémica más allá del capitalismo global. Bogotá: Siglo del Hombre Editores, Universidad Central, Instituto de Estudios Sociales Contemporáneos y Pontificia Universidad Javeriana, Instituto Pensar.

Carli, S. (2014). Ver este tiempo. Las formas de lo real. En Dussel, I. y Gutierrez, D. (Ed.). Educar la mirada. Políticas y pedagogías de la imagen. Buenos Aires: Manantial, Flacso. 
Cejas, N. (2014). Procesos Comunicacionales en Prácticas de Co-Construcción de Conocimiento. (Tesis de posgrado), Centro de Estudios Avanzados, Universidad Nacional de Córdoba, Argentina.

Dagnino, R. (2014). Tecnologia Social: contribuições conceituais e metodológicas. Campinas: EDUEPB.

De Sousa Santos, B. (2009). Una epistemología del sur: la reivindicación del conocimiento y la emancipación social. México: Siglo XXI, CLACSO.

Foucault, M. (1968). Las palabras y las cosas: una arqueología de las ciencias humanas. Buenos Aires: Siglo XXI.

Freire, P. (2002). Pedagogía del Oprimido. Buenos Aires: Siglo Veintiuno Editores.

Grosfoguel, R. (2015). Del extractivismo económico al extractivismo epistémico y ontológico. Revista Internacional de Comunicación y Desarrollo, 4, 33-45.

Guba, E. y Lincoln, Y. (2000). Paradigmas en competencia en la investigación cualitativa. En

Lander, E. (2000). Ciencias sociales: saberes coloniales y eurocéntrico. En La colonialidad del saber: eurocentrismo y ciencias sociales. Perspectivas Latinoamericanas. CLACSO, Consejo Latinoamericano de Ciencias Sociales, Buenos Aires, Argentina. Recuperado de http://bibliotecavirtual.clacso.org.ar/clacso/sur-sur/20100708040444/3_lander1.pdf

Liendo, M. (2015). Acerca de la colonialidad Jurídica. En Discursos políticos contemporáneos: espacios de Producción de conocimientos y acciones locales. II Simposio Internacional sobre Estudios Latinoamericanos: Diálogos interdisciplinarios sobre sociedad, historia, cultura, frontera y territorio (antropología, historia, ciencias sociales, geografía, música popular). Villa María, Córdoba.

Lorde, A. (2003). Las herramientas del amo nunca desarmaran la casa del amo. En Lorde, A. La hermana, la extranjera. Artículos y conferencias. Madrid: Ed. Horas y horas.

Mignolo, W. (2003). Historias locales/diseños globales. Colonialidad, conocimientos subalternos y pensamiento fronterizo. Madrid: Akal.

Mignolo, W. (2007). El pensamiento Decolonial: desprendimiento y apertura. Un manifiesto. En Castro-Gómez, S. y Grosfoguel, R. (compiladores). El giro decolonial: reflexiones para una diversidad epistémica más allá del capitalismo global. Bogotá: Siglo del Hombre Editores.

Quintero, P. (2014). Sobre la matriz colonial de poder. En Palermo, Z. (Ed.). Para una Pedagogía Decolonial. Buenos Aires: Del Signo.

Risler, J. y Ares, P. (2013). Manual de mapeo colectivo: recursos cartográficos críticos para procesos territoriales de creación colaborativa. Buenos Aires: Tinta Limón. 
Rivera Cusicanqui, S. (2015). Sociología de la Imagen. Miradas ch'ixi desde la historia andina. Buenos Aires: Tinta Limón.

Rivera Cusicanqui, S. (2003). La epistemología y sus formas cambiantes. En Bergalli, R. y Spivak, G. (2003). ¿Puede hablar el subalterno? Revista Colombiana de Antropología, 39, 297-364.

Thomas, H. (2011). Sistemas tecnológicos sociales y ciudadanía socio-técnica. diCom. Maestría en Diseño Comunicacional. Recuperado de http://maestriadicom.org/articulos/sistemas-tecnologicos-sociales-y-ciudadania-sociotecnica-2/

Vasilachis De Gialdino, I. (2007). Estrategias de investigación cualitativa. Buenos Aires: Gedisa editorial. 